\title{
Blue luminescent cyanopyridone based molecular architectures: A structure-property study
}

\author{
Trupthi DevaiahC. ${ }^{a}$, HemavathiB. ${ }^{a}$, M. Blanca Ros ${ }^{b}$, Joaquín Barberáb ${ }^{\text {, Rosa M. Tejedor }}{ }^{\text {b, c }}$,

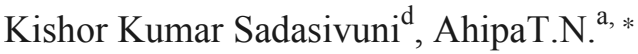 \\ a Organo-Electronics, Centre for Nano and Material Sciences, Jain University, Jain Global Campus, Kanakapura, Ramanagaram, Bangalore 562 112, India \\ ${ }^{\mathrm{b}}$ Institute of Materials Science of Aragón (ICMA), Department of Organic Chemistry, University of Zaragoza-CSIC, Zaragoza 50009, Spain \\ c Centro Universitario de la Defensa, Academia General Militar, Zaragoza 50009, Spain \\ ${ }^{\mathrm{d}}$ Center for Advanced Materials, Qatar University, P.O. Box 2713, Doha, Qatar
}

\section{A R T I C L E IN F O}

\section{Article history:}

Received 29 November 2017

Received in revised form 18 January 2018

Accepted 21 January 2018

Available online $\mathrm{xxx}$

Keywords:

Luminescent

Liquid crystal

Cyanopyridone

Cyclic voltammetry

\begin{abstract}
A B S T R A C T
A new class of molecular architecture made of five conjugated rings carrying terminal methyl or variable alkoxy (chain lengths of 4, 6, 8, or 16) substituents at para positions has been synthesized. Among the five rings, two rings are of cyanopyridones utilized as an electron deficient N-heterocycle and blue lumines-cent motif, and the rest of them are phenylene motifs. All the compounds were obtained in good yield and ATRIR, NMR and Mass spectroscopy confirmed their structures. Furthermore, the compounds were stable up to $\approx 200^{\circ} \mathrm{C}$ and the degradation occurs at higher temperature as evidenced by the TGA analysis. The mesomorphic study reveals that only the compound having very long terminal $n$-hexadecyloxy substituents showed inlayers liquid crystalline organization as confirmed by POM and variable temperature XRD analysis. Furthermore, the compounds showed intense blue fluorescence in both solution as well as solid state and their fluo-rescence quantum yields are dependent on the length of alkoxy chains. Calculated HOMO/LUMO levels by cyclic voltammetry measurements revealed that the compounds are ambipolar in nature and proposed to be ideal candidates for electroluminescent applications.
\end{abstract}

\section{Introduction}

In the recent years, tuning of photophysical properties of organic moieties based on their state, size, molecular framework, and change in functionalities have drawn a lot of interest, as tuning of these properties allows to achieve organic moieties with desired characteristic behavior. However, the area of synthesizing new luminescent organic moieties showing emission over a wide range in the solid state is still challenging and is of great interest to many researchers. In this frame, a number of recent research has confirmed that alkyl chain length could influence on the molecular conformations, intermolecular interactions and packing modes in solid state, thus, alters the solid state optical and optoelectronic properties [1-5]. Hence, varying of alkyl chain lengths has a functional role in determining the solid-state aggregation and optoelectronic behavior of organic motifs. The extensively studied luminescent materials exhibiting alkyl length-reliant fluorescence properties contains twisted conformations, usually exhibit aggregation induced emission (AIE) [6], mechanochromic luminescence [7-9] phenomenon and weak solution fluorescence quantum yield. In the literature, some of the cyanopyridone derivatives were reported to be electron deficient and strong blue emitters with high quantum yields [10-12]. Because of these properties, the present

\footnotetext{
* Corresponding author.

Email address: tn.ahipa@jainuniversity.ac.in (T.N. Ahipa)
}

study concerns the luminescent cyanopyridone core bearing methyl and linear alkoxy substituent and their photo-physical properties in various solvent mixtures being inquisitive about the emission behavior upon aggregation.

On the other hand, few reports are available on liquid crystalline cyanopyridones with a rod-shaped molecular structure and polymerisable cyanopyridones [13]. Also, it is well established that the incorporation of cyanopyridone unit helps to attain high polarity and high positive values of the dielectric anisotropy mainly due to the presence of cyano and keto groups at adjacent positions in the ring [14]. Cyano group being a well-known electron withdrawing substituent, the incorporation of cyano group as a substituent in the molecular framework further increases the molecular dipole moment and thereby, minimize the repulsive interactions between adjacent aromatic $\pi$-systems and promotes the formation and stabilization of mesophase [15]. In addition, pyridone motifs have the greater tendency to self-assemble into columnar discotic mesophase via hydrogen bond interactions $[16,17]$. In contrast, polycatenar mesogens, particularly the penta-catenar compounds showed interesting mesophases viz. smectic, cubic and columnar phases. These mesophase formations are generally assisted by the number of rings present in the core, the type and number of terminal chains, the nature of the bridging groups etc. [18]. Keeping all the above facts in view and the availability of limited reports on the luminescent cyanopyridone unit, we have designed new five ring system carrying two cyanopyridones based molecular architecture in the present work. 
In the present study, we have incorporated two 3-cyanopyridone units as luminescent core to achieve five ring molecular framework. Both the terminals of molecular frameworks have been substituted by the methyl or linear alkoxy groups (length of chain=4, 6, 8, or 16) at their para position to get new cyanopyridone derivatives (AC1-5). These molecules were prepared from one pot synthesis method by reacting 4-methyl acetophenone/4-alkoxy acetophenone, terepthaldehyde, ethyl cyanoacetate and ammonium acetate. Later, ATR-IR, NMR and Mass spectroscopy elucidated their chemical structures. Their photophysical properties were determined by UV-visible absorption and fluorescence emission studies. The target compounds were subjected to TGA (thermogravimetric analysis), DSC (differential scanning calorimetry), POM (polarized optical microscopy) and variable temperature X-ray diffraction (XRD) analysis to check their underlying thermal stability as well as liquid crystalline behavior. Surface features of thin films of selected compounds were extracted with the help of AFM. Finally, electrochemical band gap, LUMO and HOMO energy levels were determined using cyclic voltammetry method.

\section{Results and discussion}

\subsection{Synthesis and characterization}

The synthetic route for the preparation of the target molecules is depicted in Scheme 1. The general procedure for the preparation of long chained alkoxyacetophenones (1b-e) are same as reported earlier [19]. Target bicyanopyridone compounds (AC1-5) were synthesized by a one pot method by reacting the mixtures of methyl/alkoxyacetophenones (1a-e) with terephthaldehyde (2), ethyl cyanoacetate and ammonium acetate $(0.16 \mathrm{~mol})$ in 1,4 -dioxane under $80^{\circ} \mathrm{C}$ for $8 \mathrm{~h}$. All the target compounds were obtained in good yield $(>70 \%)$. The structures of all the target molecules were confirmed using ATR-IR, NMR spectroscopy and Mass analysis.

\subsection{Thermal behavior}

Thermal stability of all the target compounds was investigated with the help of thermogravimetric analysis (TGA) and also by POM. Cyanopyridone derivatives (AC1-5) were instable above $200^{\circ} \mathrm{C}$ as evidenced by the TGA (Fig. 1). The temperature degradation depends on the terminal chain lengths, but this fact did not allow to fix their melting temperatures as cyanopyridone derivatives decompose before melting, with the exception of AC5 that decomposes before passing to isotropic liquid from mesophase as detailed later.

\subsection{Photophysical properties}

Solution state UV-visible absorption spectra of AC1-5 compounds were recorded at the concentration $1 \times 10^{-5} \mathrm{M}$ in DMSO. The values of absorption maximum of AC1-5 are given in Table 1 and their absorption spectra is depicted in Fig. 2. As can be seen, the absorption spectra obtained for the solutions of AC1-5 showed a single absorption maximum in a range of $385-394 \mathrm{~nm}$ and these absorption bands can be attributed to the spin allowed $\pi-\pi^{*}$ transitions in them. In general, more the planar molecular framework greater the extant of delocalization of $\pi$ electrons, which narrow the band gap and shifts the absorption wavelength to longer wavelength region (red shift). However, the obtained absorption values for compounds AC1-5 in DMSO are almost same when compared to our earlier report of the three ring system containing a central cyanopyridone core [20]. Further, compounds exhibited larger values of molar absorption coefficient $(\varepsilon)>17,000 \mathrm{~L} \mathrm{~mol}^{-1} \mathrm{~cm}^{-1}$ and showed how strongly these substances absorb light. The variation of alkoxy chain lengths in the compounds affects the absorption wavelength and molar extinction coefficient. Among AC1-5, the highest absorption wavelength and molar extinction coefficient are noted for AC3 (carrying n-hexyloxy chains) and AC2 (carrying n-butyloxy chains), respectively. It is interesting to note that, as we varied the alkoxy chain lengths from n-butyloxy to n-hexyloxy chains, the bathochromic shift occurs, but later on the further increase of chain lengths n-hexyloxy to n-octyloxy or n-hexadecyloxy chains exhibited a hypsochromic shift. This can be accounted on the basis of steric factor, wherein, the presence of higher alkoxy chains causes a greater steric hindrance leading to attain a highly distorted chain conformation with shorter $\pi$-conjugation length in the molecule [21]. Thus, the extent of molecular planarity is more in case of AC3 (carrying n-hexyloxy chains) than the rest of compounds, which resulted in the absorption at longer wavelength region [22].

Fluorescence emission spectra of cyanopyridone compounds (AC1-5) were recorded in DMSO (Conc. $1 \times 10^{-5} \mathrm{M}$ ) by exciting the solutions of these compounds at their absorption maxima, leading to emissions band with their maxima centered at around $456-474 \mathrm{~nm}$ (Fig. 3) and displaying large Stokes shift (range: 69-81 nm) values. In solution state, all the compounds are blue emissive in nature. Further, their relative quantum yield $\left(\Phi_{\mathrm{f}}\right)$ in solution state were determined using quinine sulphate in $0.1 \mathrm{M}$ sulfuric acid as a standard $\left(\Phi_{\mathrm{f}}=0.54\right)$ [23-25]. The compounds displayed a varied quantum yields $\left(\Phi_{\mathrm{f}}=0.08-0.36\right)$, among them, compound AC4 was exhibited a highest quantum yield. It is observed that, the fluorescence quantum yield improved with the increase of alkoxy chain lengths till n-octyloxy chain, thereafter, no drastic change was noted with the n-hexa-<smiles>[R]c1ccc(-c2cc(-c3ccc(-c4cc(-c5ccc([R])cc5)c(C#N)c(=O)[nH]4)cc3)c(C#N)c(=O)[nH]2)cc1</smiles>

where, $\mathrm{R}=-\mathrm{CH}_{3}$ for $\mathbf{1} \mathbf{a}$ and $\mathbf{A C 1}$

$\mathrm{R}=-\mathrm{OC}_{4} \mathrm{H}_{9}$ for $\mathbf{1 b}$ and $\mathbf{A C 2}$

$\mathrm{R}=-\mathrm{OC}_{6} \mathrm{H}_{13}$ for $\mathbf{1 c}$ and $\mathbf{A C 3}$

$\mathrm{R}=-\mathrm{OC}_{8} \mathrm{H}_{17}$ for $\mathbf{1 d}$ and $\mathbf{A C 4}$

$\mathrm{R}=-\mathrm{OC}_{16} \mathrm{H}_{33}$ for $\mathbf{1 e}$ and $\mathbf{A C 5}$

Scheme 1. Synthetic route for AC1-5. 


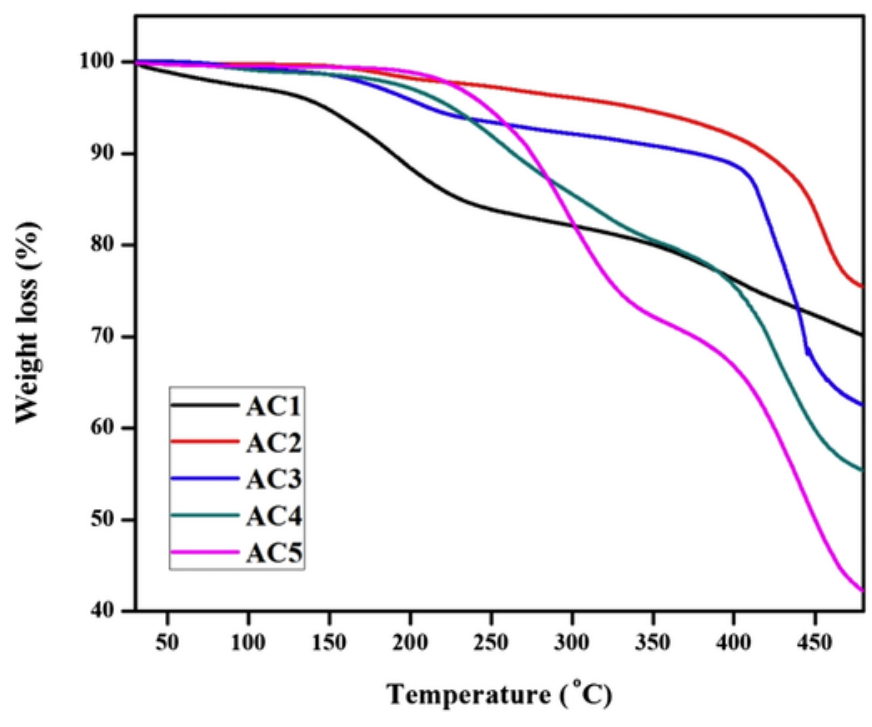

Fig. 1. TGA thermograms of AC1-5.

decyloxy chain [26]. Also, UV-visible absorption spectra of AC1-5 were recorded in thin film state (Fig. S15) and showed a slight hypsochromic shift in their absorption band to that of solution state. Further, their optical band gaps $\left(\mathrm{E}_{\mathrm{g}}\right)$ were estimated by considering the wavelength of absorption edge in their thin film state and they were found to be in the range of $2.77-2.88 \mathrm{eV}$. In general, fluorescence properties of compounds in their film state are also required in order to identify the suitability of these compounds in OLED application [27]. All the compounds exhibited good film forming ability. Thus, we examined the emission properties of AC1-5 in thin film state and found that their blue emission bands (Fig. S16) are slightly shifted to longer wavelength region compared to that of solution state.

A number of recent examinations have clearly confirmed that compounds bearing alkyl chain length could define the nature of intermolecular interaction, solid-state optical and optoelectronic properties as well [1-5]. Further, alkyl chains play a functional role in determining the solid-state aggregation, optimizing the intermolecular $\pi-\pi$ and aliphatic interaction as well as molecular packing. Introduction of long alkyl chains are known to increase the intermolecular distance between neighboring molecules which can induce AIE. However, they can also induce disorder in molecular arrangements and reduce the emission process [28].
To evaluate whether the cyanopyridone based conjugated compounds were AIE active, their emission behaviors in solvent-nonsolvent mixtures were determined. The studies were made in THF/water and DMSO/water systems. All the AC1-5 compounds are highly soluble in polar aprotic DMSO solvent but insoluble in water. In case of AC1-3, using the DMSO/water as the mixed solvent and increasing the water fraction 0 to $90 \%$ would cause the decrease in emission intensity (Fig. S2-4). However, the compound AC4 with $10 \%$ water fraction showed the highest emission intensity (Fig. 4a) and a slight red shift in the emission wavelength $(470 \mathrm{~nm})$ was noted, which may be due to the stronger molecular aggregation and the acquired planar molecular framework in it. Even, the compound at 20\% water fraction exhibited slightly higher emission intensity and blue shift in wavelength compared to the compound at $0 \%$ water fraction (emission at $467 \mathrm{~nm}$ ). Later on, the increase of water fraction up to $60 \%$ decrease the emission intensity and the blue shift in emission wavelengths were noted. This can be attributed to aggregation of molecules could result in the twisting of molecular framework and slightly increasing in the energy of band gap, hence the observed hypsochromic shift or blue shift. Furthermore, the compound once again causes a slight increase in emission intensity and a considerable red shift in the wavelength $(\sim 505 \mathrm{~nm})$ with broad emission profile with the 70 and $80 \%$ water fraction. However, the emission intensity decreased a bit once again at $90 \%$ water fraction. Curves of fluorescent intensity vs. water fraction and emission images of the compounds in DMSO/water solution with a $254 \mathrm{~nm}$ UV lamp are depicted in Fig. 4b and Fig. 4c, respectively. However, the AIE investigation study on compound AC4 suggests that the molecular aggregation causes molecules to acquire various conformational forms upon the increase of water fraction. Also, red-shifted emission wavelength $(\geq 70 \%)$ during the process is attributed to the twisted intramolecular charge transfer effect. However, in case of compound AC5, emission intensity decreases with the increase of water fraction except with 60 and $\geq 80 \%$ of water fraction, which showed characteristic AIE effect (Fig. S5).

On the other hand, AIE studies of AC1-5 were investigated in $\mathrm{THF} /$ water mixtures, and their emission spectra were recorded. The emission slightly increased with the addition of water up to $30 \%$ water fraction, followed by non-uniform quenching of emission intensity on further addition in AC1-3 and AC5. Fluorescence emission spectra of AC3 in THF/water with different water fraction, a graph of fluorescent intensity vs. water fraction, and emission images of the compounds in THF/water solution with a $254 \mathrm{~nm} \mathrm{UV} \mathrm{lamp} \mathrm{is} \mathrm{shown}$ in Fig. 5a-c. The emission gradually quenched with the addition of water in AC4, arising from increased solvent polarity and increase in immiscibility of AC4 with increasing water concentration. As a whole, the emission intensity of $\mathbf{A C}$ series in THF solution increases

Table 1

Photophysical properties of AC1-5.

\begin{tabular}{|c|c|c|c|c|c|c|c|c|c|}
\hline Sample & $\begin{array}{l}\lambda_{\max }^{a b s a} \\
(\mathrm{~nm})\end{array}$ & $\begin{array}{l}\varepsilon \\
\left(\mathrm{L} \mathrm{mol}^{-1} \mathrm{~cm}^{-1}\right)\end{array}$ & $\begin{array}{l}\lambda_{\max }^{e m a, b} \\
(\mathrm{~nm})\end{array}$ & $\begin{array}{l}\text { Stokes shift } \\
(\mathrm{nm})\end{array}$ & $\Phi_{\mathrm{f}}^{\mathrm{c}}$ & $\begin{array}{l}\lambda_{\max }^{a b s \mathrm{~d}} \\
(\mathrm{~nm})\end{array}$ & $\begin{array}{l}\lambda_{\max }^{e m \mathrm{~d}} \\
(\mathrm{~nm})\end{array}$ & $\begin{array}{l}\lambda_{\text {a.e. }}{ }^{\mathrm{f}} \\
(\mathrm{nm})\end{array}$ & $\begin{array}{l}E_{g}^{\text {Optg }} \\
(\mathrm{eV})\end{array}$ \\
\hline AC1 & 385 & 17,000 & 461 & 76 & 0.13 & 374 & 463 & 430 & 2.88 \\
\hline AC2 & 393 & 69,000 & 473 & 80 & 0.18 & 390 & 487 & 447 & 2.77 \\
\hline AC3 & 394 & 52,000 & 474 & 80 & 0.27 & 383 & 479 & 446 & 2.78 \\
\hline AC4 & 390 & 49,000 & 471 & 81 & 0.36 & 376 & 479 & 439 & 2.82 \\
\hline AC5 & 387 & 35,000 & 456 & 69 & 0.32 & 372 & 472 & 437 & 2.83 \\
\hline
\end{tabular}

${ }^{a}$ Solution in DMSO $\left(1 \times 10^{-5} \mathrm{M}\right)$.

${ }^{\text {b }}$ Excited at the respective absorption maxima.

c Relative quantum yield method using quinine sulphate as standard.

d Thin film.

${ }^{f}$ Absorption edge in the thin film state.

${ }^{g}$ Formula $\mathrm{E}_{\mathrm{g}}(\mathrm{eV})=1240 / \lambda_{\text {a.e. }}(\mathrm{nm})$. 


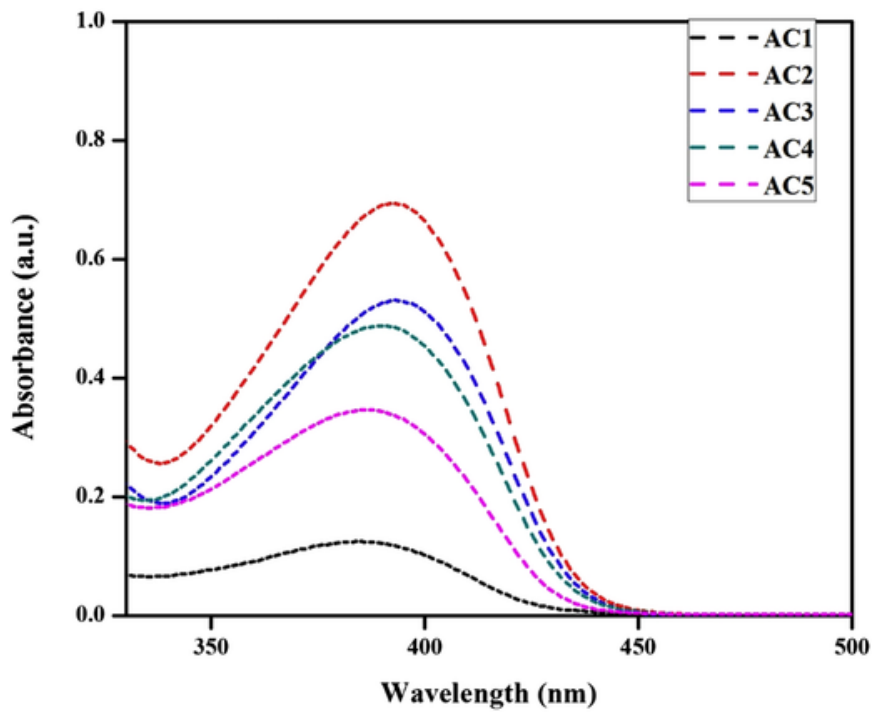

Fig. 2. UV-visible absorption spectra of AC1-5 in DMSO (Conc. $1 \times 10^{-5} \mathrm{M}$ ).

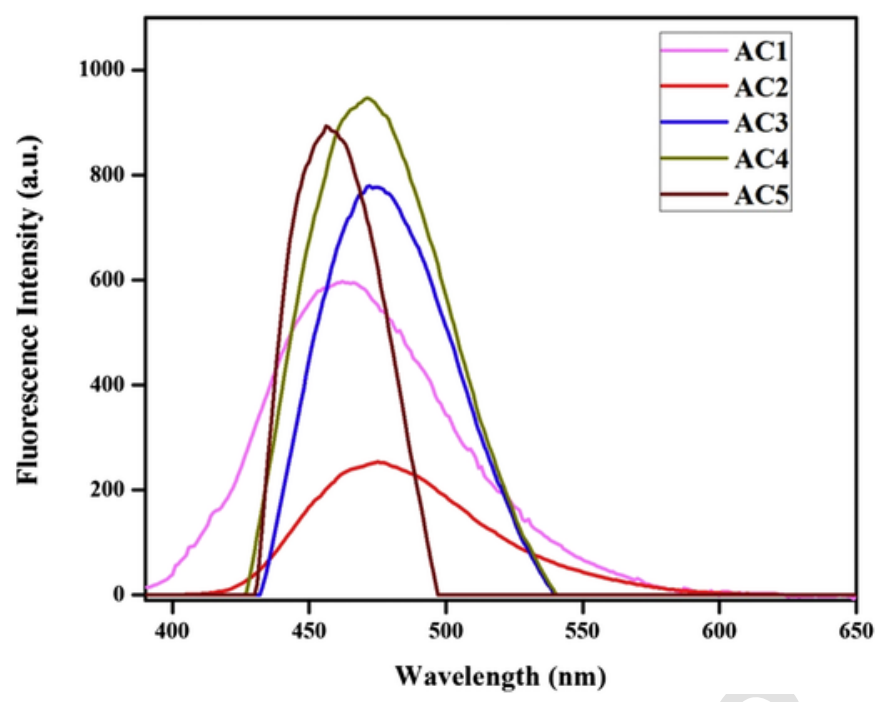

Fig. 3. Fluorescence emission spectra of AC1-5 in DMSO (Conc. $1 \times 10^{-5} \mathrm{M}$ ).

from AC1-3 followed by a further decrease in emission intensities are observed in AC4 and AC5 (Fig. S7-10). This infers that the introduction of alkoxy chains and the extending of alkyl chain lengths could decrease the fluorescence efficiency [29]. Also, the emission intensity of organic chromophores bearing at least one $\pi$ deficient substituent (cyano or nitro) are reported to weaken in polar solvents owing to the formation of less emissive ICT state [30,31]. The emission peak red-shifted from AC1-4 followed by a slight blue shift in AC5. In case of AC1, the emission peak exhibits bathochromic shift up to $60 \%$ water fraction, on further addition of water the peaks are observed to shift hypsochromically from 70 to $90 \%$ water fraction. Whereas in AC2, the bathochromic shift is observed only till $50 \%$ water fraction followed by slight hypsochromic shift further up to $90 \%$ water fraction. Further in AC3, the emission peak shifts bathochromically only up to $30 \%$ water fraction preceded by a hypsochromic shift thereafter till $90 \%$ water fraction. While in AC4, a steady bathochromic shift is only observed till $20 \%$ water fraction followed by a non-uniform shift in emission peak wavelength. Inter- estingly, AC5 shows a hypsochromic shift up to $60 \%$ water fraction followed by bathochromic shift further up to $90 \%$ water fraction. The emission peak of AC1-4 in THF exhibits red-shift, whereas, AC5 is observed to shift towards the blue region. Hence, side chain engineering can be exploited to tune the optical and optoelectronic properties of organic moieties. The emission color and intensity show some irregularity after the water content reaches a critical value, possibly due to the formation of different aggregation states such as crystal particle and amorphous particles. From the above results, the maximum fluorescence intensity is observed for AC3 having alkyl substitution of 6-carbons while a decrease in fluorescence intensity was observed for alkyl substitution of 16-carbons. Same kind of observations can be made in their solid states. To support this, photographs of compounds AC1-5 showing color emissions in solid and solution states under day light and short UV $(254 \mathrm{~nm})$ illumination is depicted in Fig. 6.

\subsection{Cyclic voltammetry}

Cyclic voltammetry (CV) measurement helps to determine the underlying HOMO/LUMO energy levels and an electrochemical band gap of organic molecules. All the cyanopyridone derivatives AC1-5 were investigated for their electrochemical behavior by carrying out $\mathrm{CV}$ studies in anhydrous acetonitrile solution. The energy levels and band gaps calculated from these studies are tabulated in Table 2. A $0.1 \mathrm{M}$ solution of tetrabutylammonium hexaflurophospate (TBAH) was used as a supporting electrolyte in deoxygenated acetonitrile. For $\mathrm{CV}$ measurement, a single compartment cell equipped with $\mathrm{Ag} / \mathrm{Ag}^{+}$ wire (reference electrode), platinum rod (counter electrode) and glassy carbon (working electrode) were used. The reference electrode was calibrated with the ferrocene/ferrocenium $\left(\mathrm{Fc} / \mathrm{Fc}^{+}\right)$redox couple (absolute energy level of $-4.80 \mathrm{eV}$ to vacuum and ionization potential for $\mathrm{Fc} / \mathrm{Fc}^{+}$measured was $+0.53 \mathrm{eV}$ vs. $\mathrm{Ag} / \mathrm{AgCl}$ ). The cyclic voltammograms were recorded at a scan rate of $50 \mathrm{mV} / \mathrm{s}$. All the compounds exhibited well-defined irreversible oxidation and reduction curves (Fig. 7). To calculate HOMO and LUMO levels of the molecules oxidation potential ( $\left.E_{\text {onset }}^{o x}\right)$ and reduction potential $\left(E_{\text {onset }}^{\text {red }}\right)$ values are essential. The oxidation and reduction potentials values for the molecules were obtained in the range of +1.06 to $+1.13 \mathrm{eV}$ and -0.49 to $-0.57 \mathrm{eV}$, respectively. Further, HOMO and LUMO levels of the molecules were calculated using the formula $E_{H O M O}=-\left[E_{\text {onset }}^{o x}+4.27 \mathrm{eV}\right]$ and $E_{L U M O}=-\left[E_{\text {onset }}^{r e d}+4.27 \mathrm{eV}\right]$, respectively. Upon calculation, it is evident that these molecules possess their HOMO and LUMO energy levels at around -5.33 and $-3.75 \mathrm{eV}$, respectively. Also, electrochemical band gap of about $1.60 \mathrm{eV}$ were achieved for the cyanopyridone functionalized molecular architecture. Here, the obtained electrochemical band gap values $(\sim 1.60 \mathrm{eV})$ from $\mathrm{CV}$ measurements are slightly different from the one calculated from their optical band gap values. According to Tang et al., the materials with $\mathrm{LUMO}<-3.15 \mathrm{eV}$ and $\mathrm{HOMO}>-5.6 \mathrm{eV}$ exhibits strictly ambipolar behavior [32]. Our compounds showed HOMO/LUMO levels within the aforementioned range, thus, the compounds are ambipolar in nature and proposed to be ideal candidates for electroluminescent applications [33].

\subsection{Liquid crystal properties}

Compounds AC1-5 were studied by POM, D SC, and XRD at variables temperatures in order to explore their liquid crystal properties. Only AC5 with long terminal tails showed evidence of mesomorphic behavior; however optical textures under the microscope did not allow the unambiguous assigning the type of mesophase (Fig. 
a)

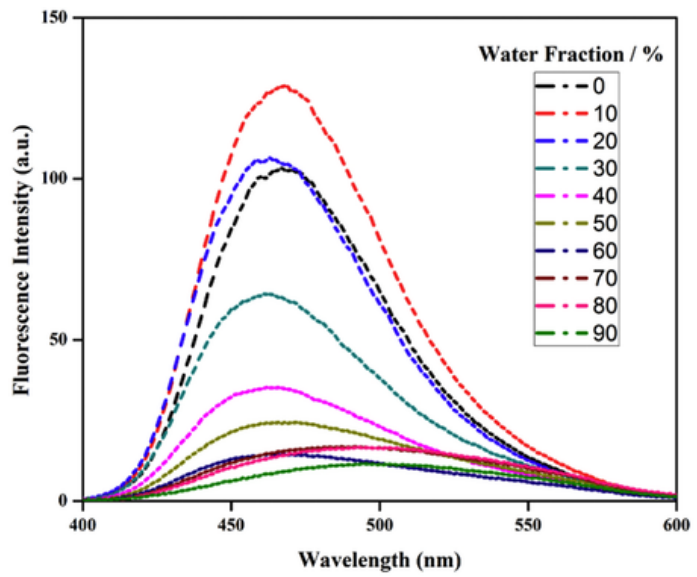

b)

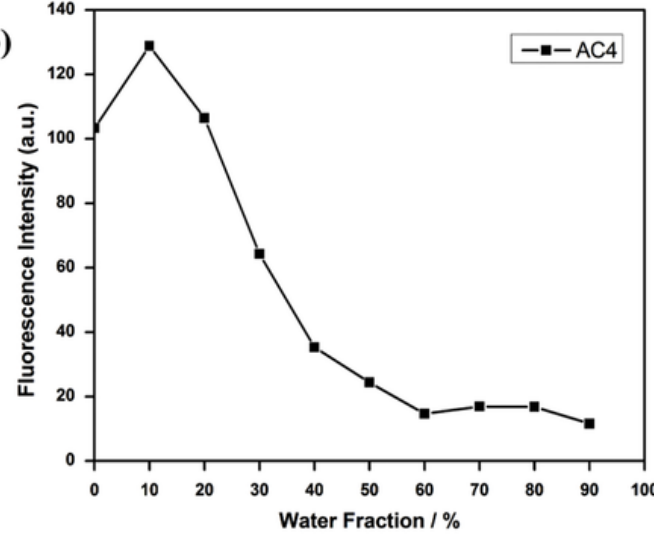

c)

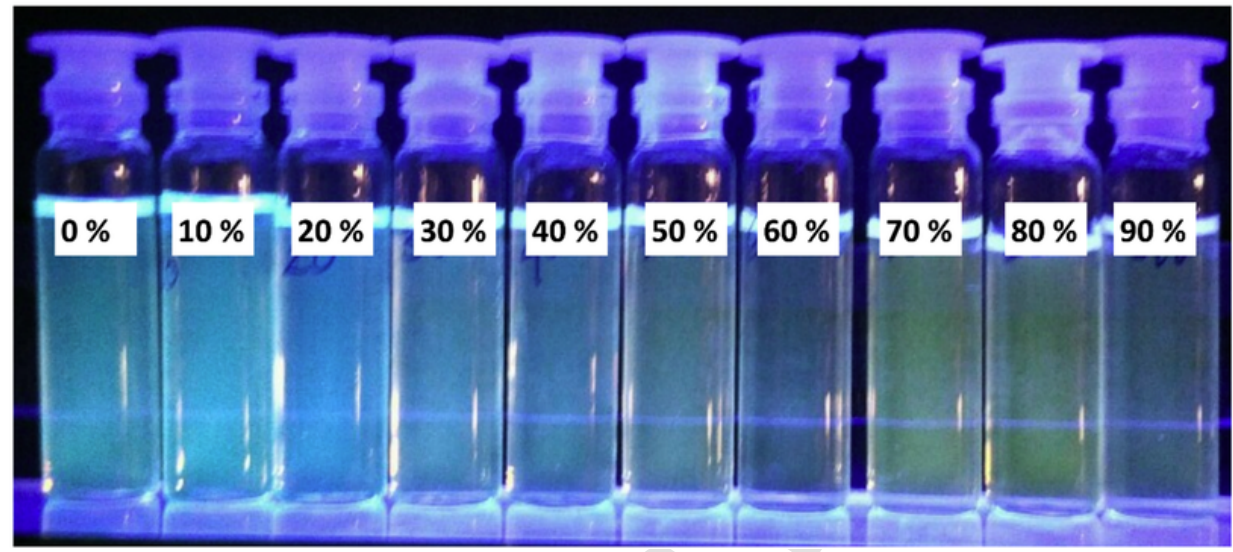

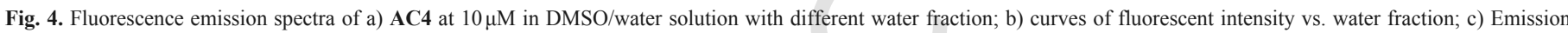
images of the compounds in DMSO/water solution with a $254 \mathrm{~nm}$ UV lamp.

S11). The DSC curves recorded on different heating and cooling processes of AC5 (see DSC traces at Fig. S11) contain a set of transition peaks that supported the mesomorphic behavior. Combination of DSC and POM data advised that a mesophase is present above $140^{\circ} \mathrm{C}$ on heating, but the compound decompose reaching $180-190^{\circ} \mathrm{C}$ in a similar way to the rest of the compounds of the series.

To confirm our proposal, compound AC5 was studied by X-ray diffraction at variable temperatures to explore the existence of a liquid crystal phase above the melting of the crystalline solid. To this aim, $\mathrm{X}$-ray patterns were recorded in all temperature regions above and below each transition peak detected by DSC. Thus, experiments were carried at room temperature (before and after the studies at high temperatures), and also at $76^{\circ} \mathrm{C}, 118^{\circ} \mathrm{C}, 150^{\circ} \mathrm{C}$, and then at $120^{\circ} \mathrm{C}$ and $150^{\circ} \mathrm{C}$ according to the different DSC peaks and avoiding the decomposition of the sample. The X-ray patterns recorded at room temperature both before and after thermal treatments, as well as at $81^{\circ} \mathrm{C}$ and at $118^{\circ} \mathrm{C}$, (see Fig. S12) were characteristic of a 3D crystalline structure, although with a significant degree of disorder as suggested by the absence of diffraction maxima at low angles and the presence only of diffuse scattering in this angular region. However, the presence of several sharp reflections at middle and high angles unequivocally shows the crystalline character of the sample.

On the other hand, the two patterns recorded at $150^{\circ} \mathrm{C}$ and the pattern at $120^{\circ} \mathrm{C}$ after cooling from $150^{\circ} \mathrm{C}$ are characteristic of a mesophase of $\mathrm{A}$ or $\mathrm{C}$ type. The patterns contain a set of two equally-spaced sharp reflections at low angles and a diffuse scattering halo at high angles (see Fig. S13). The diffuse scattering at low angles and the sharp reflections at middle and high angles observed in the previ- ous patterns are no longer present. This indicates that a phase transition has taken place to a mesomorphic phase upon heating up to $150^{\circ} \mathrm{C}$ and this mesomorphic phase is maintained by cooling down to $120^{\circ} \mathrm{C}$ and heating again up to $150^{\circ} \mathrm{C}$. The fact that the mesophase is kept by cooling from $150^{\circ} \mathrm{C}$ to $120^{\circ} \mathrm{C}$ is consistent with the DSC results.

Each low-angle maxima corresponds in the three cases $\left(150^{\circ} \mathrm{C}\right.$, $120^{\circ} \mathrm{C}$ and $150^{\circ} \mathrm{C}$ ) to a spacing of $32.4 \AA$ and $16.2 \AA$, respectively. This is coherent with a lamellar structure with layer periodicity $32.4 \AA$ and the two maxima are respectively the first and second order reflections from the layers. The diffuse halo corresponds roughly to an average distance of $4.6 \AA$, and its broad character is typical of many kinds of mesophase. It is related to the liquid-like arrangement of the hydrocarbon chains and corresponds to the mean lateral distances between neighboring molecules. After long exposure times, some sharp reflections become visible at middle and high angles, which suggests progressive crystallization probably related to thermal instability. The absence in the low-exposure-time patterns of sharp reflections at high angles and the presence only of diffuse scattering in this angular region suggests a smectic A or smectic $\mathrm{C}$ mesophase. However, it is not possible to distinguish between the two mesophase types on the basis of powder X-ray diffraction measurements.

By simple calculations based on the molecular mass, the layer spacing and the expected density for organic compounds (ca. $\left.1 \mathrm{~g} / \mathrm{cm}^{3}\right)$, the average cross-section area of the molecules in the mesophase can be estimated. Indeed, the density $\rho$ of a smectic mesophase is related to the molecular mass $M$ and the layer spacing $d$ by the following equation: 

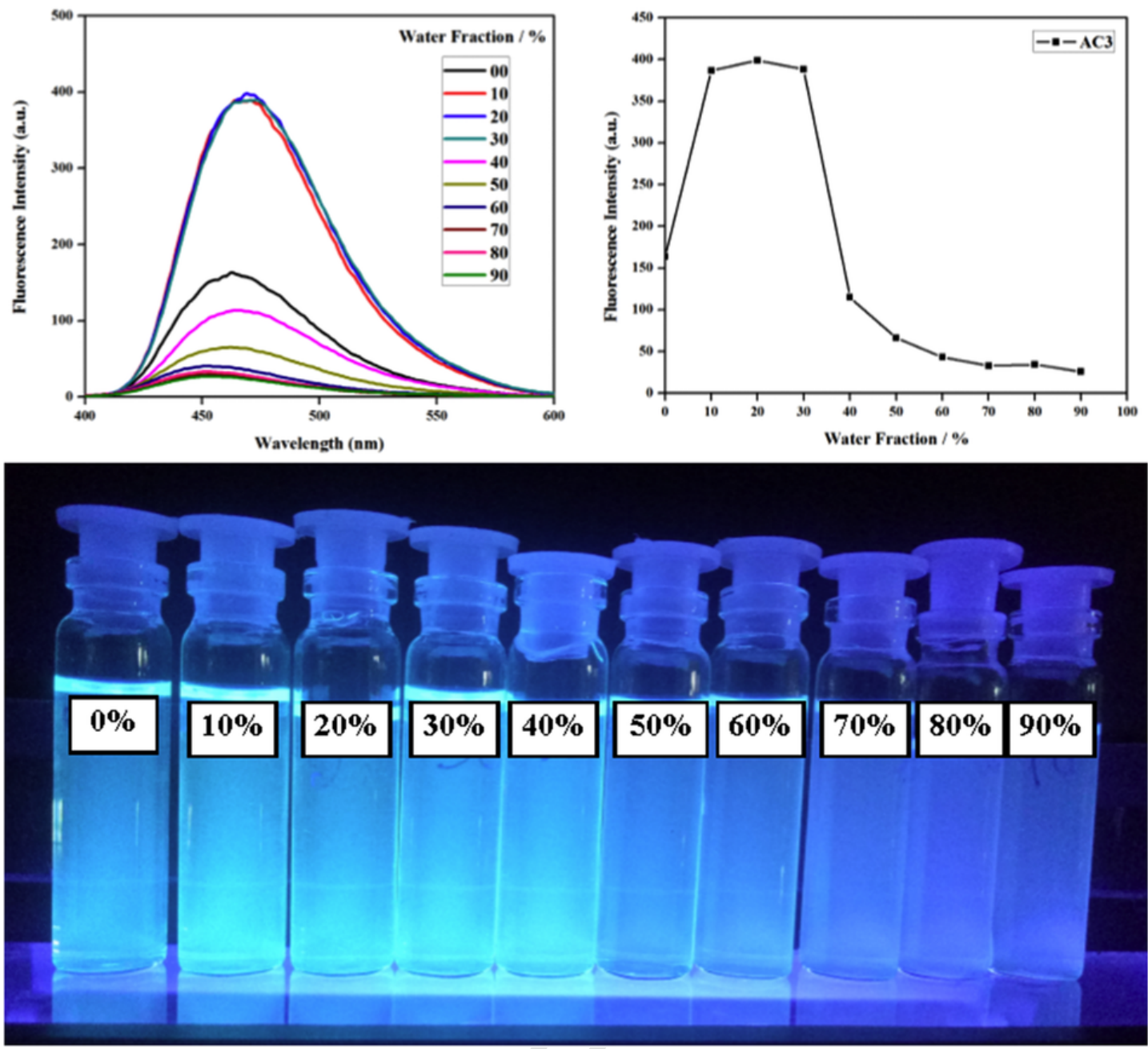

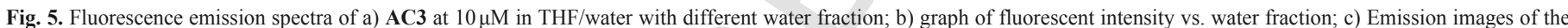
compounds in THF/water solution with a $254 \mathrm{~nm}$ UV lamp.

$$
\rho=\left(M \times 10^{24}\right) /\left(d \times S \times N_{A}\right)
$$

where $S$ is the molecule cross-section area, and $N_{A}$ is Avogadro's number. Assuming that the density is $1 \mathrm{~g} \mathrm{~cm}^{-3}$, an estimated area $S$ of about $48.5^{2}$ is obtained, which is a value larger than the usual values for orthogonal smectic phases. This suggests that the molecules are tilted in the layers ( $\mathrm{SmC}$ mesophase) and/or that interdigitation takes place between molecules in adjacent layers, both phenomena producing a larger effective cross-section. Interdigitation would not be surprising given the peculiar shape of the molecules of AC5, containing a rigid region with two bents that must produce a widening compared to classical rod-like molecules.

Unfortunately, none of the compounds synthesized has been able to yield single crystals, so it has not been possible to propose and support a certain supramolecular organization of AC5 within the mesophase based on a crystalline structure. However, according to the structural parameters of the smectic mesophase of AC5 above detailed and the crystalline structures of rather similar compounds reported by Chopra et al. [34] we propose an interdigitated smectic mesophases as shown in Fig. 8. This type of supramolecular organization is sta-bilized through a hydrogen bond network and could sup port a lamellar arrangement with an interlayer spacing of around $32.4 \AA$ depending on interdigitation. To evaluate this proposal, the model compound ACOMe (Fig. 9) was optimized at the B3LYP level with the van der Waals correction and using 6-31G(d) basis set, as a first approximation that has proved sufficient to support our proposed supramolecular order. The optimized structure of the model compound revealed that the pyridone rings are coplanar between them and not coplanar with the rest of the aromatic rings (Fig. 9). Following the evaluation of the proposed model, the hydrogen bonded dimer of ACOMe (Fig. 9) was optimized, taking the structural parameters of the crystalline networks based on hydrogen bonding published by Chopra et al. [34] as a starting point for geometry optimization of the dimer. The BSSE corrected interaction energy of the optimized dimer due to four non-covalent interactions, two hydrogen bonds $\mathrm{N}-\mathrm{H} \cdots \mathrm{O}$ and two other $\mathrm{C}-\mathrm{H} \cdots \mathrm{O}$ is negative $\left(-102.8 \mathrm{~kJ} \mathrm{~mol}^{-1}\right)$. Furthermore, the calculated infrared spectra of ACOMe and its hydrogen-bonded dimer were compared to experimental IR spectrum of a solid sample of AC5 (Fig. 10). The main difference between the calculated IR spectra is the presence of two intense bands in the spectrum of the dimer ( $f$ and a) that are attributed to the stretching frequencies of the $=\mathrm{C}$. The band at a higher frequency corresponds to the-free $\mathrm{C} \quad \mathrm{O}(\mathrm{f})$ and the one that appears at a lower frequency to the associated carbonyl group (a). While the 


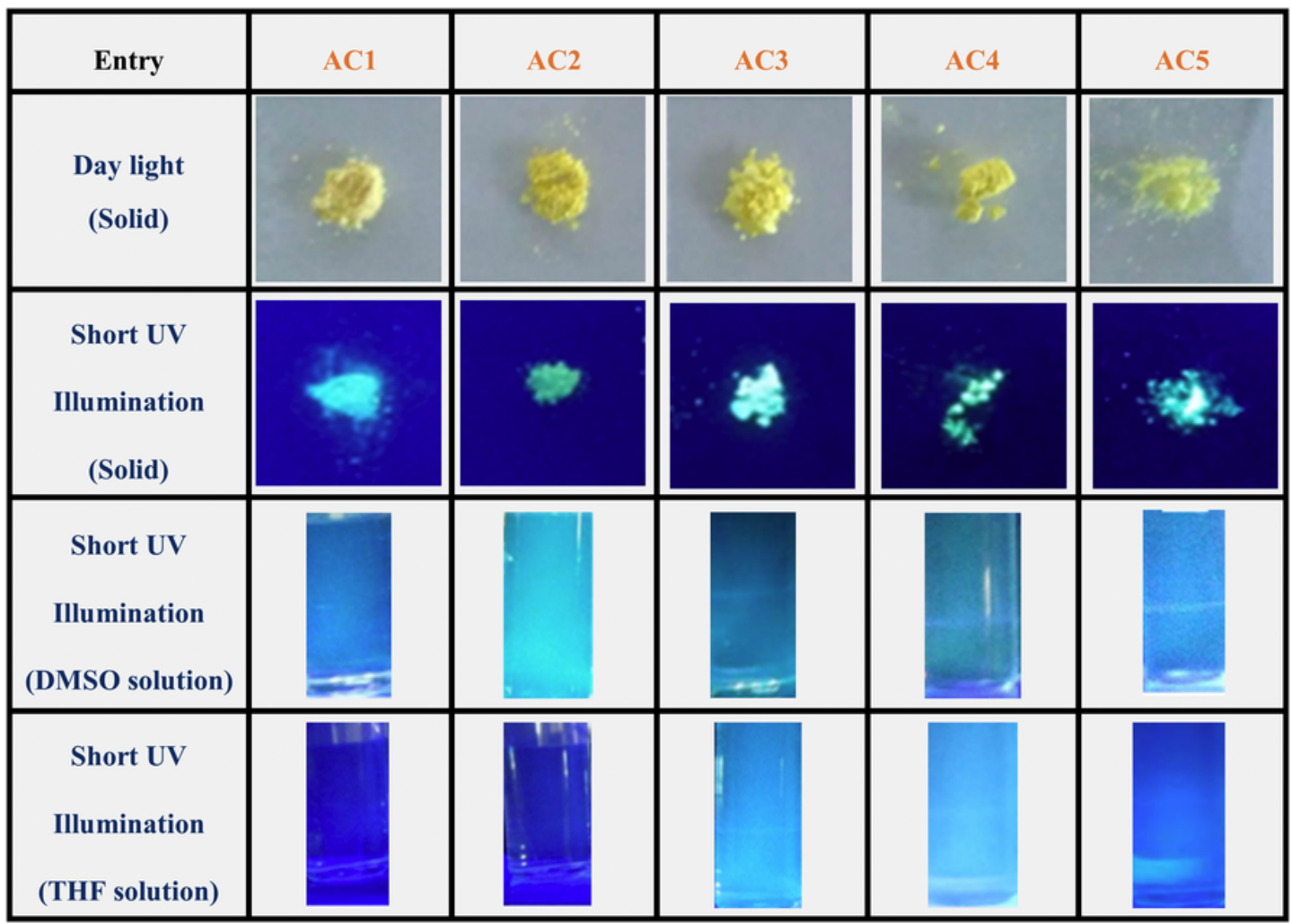

Fig. 6. Photographs of compounds AC1-5 showing color emissions in solid and solution state under day light and short UV (254 nm) illumination.

Table 2

Electrochemical properties of AC1-5.

\begin{tabular}{llllll}
\hline Entry & $E_{\text {onset }}^{o x}$ & $E_{\text {onset }}^{\text {red }}$ & $\mathrm{E}_{\mathrm{HOMO}}(\mathrm{eV})$ & $\mathrm{E}_{\mathrm{LUMO}}(\mathrm{eV})$ & $E_{g}{ }^{C V}(\mathrm{eV})$ \\
\hline $\mathbf{A C 1}$ & 1.11 & -0.49 & -5.38 & -3.78 & 1.60 \\
AC2 & 1.06 & -0.52 & -5.33 & -3.75 & 1.57 \\
AC3 & 1.08 & -0.56 & -5.35 & -3.71 & 1.63 \\
AC4 & 1.07 & -0.55 & -5.34 & -3.72 & 1.61 \\
AC5 & 1.13 & -0.57 & -5.40 & -3.70 & 1.69 \\
\hline
\end{tabular}

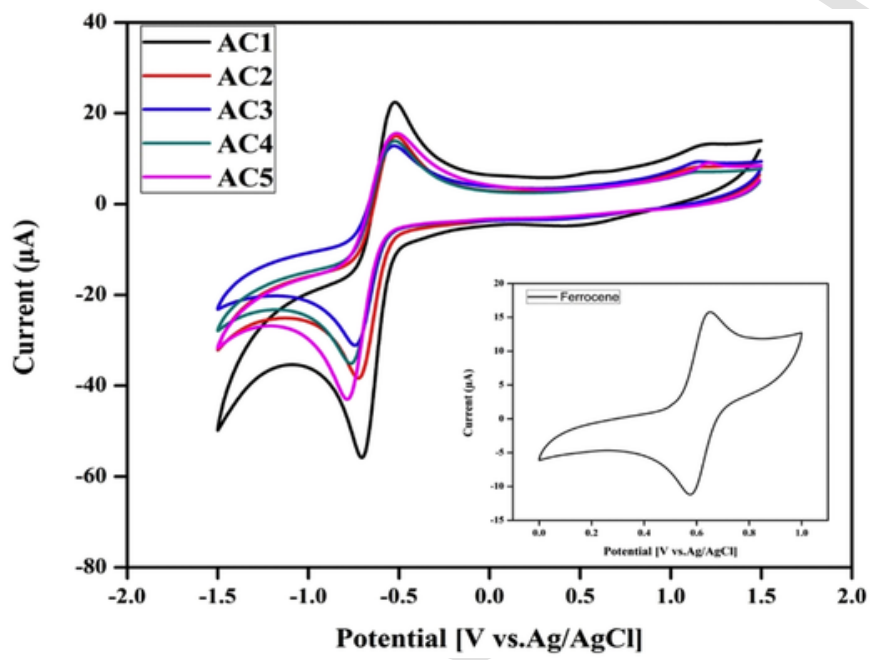

Fig. 7. Cyclic voltammogram of $\mathbf{A C 1}-\mathbf{5}$ in acetonitrile (inset: graph of $\mathrm{Fc} / \mathrm{Fc}^{+}$).
ACOMe spectrum only exhibits the carbonyl band corresponding to the free carbonyl groups. The experimental FT-IR spectrum of AC5 and the calculated infrared spectrum of the optimized dimer show a good consistency corroborating the existence of free and associated car-bonyl groups. Although these results, interaction energy, and vibra-tional spectra, are computed for dimers in optimal geometry undis-turbed by their surroundings (gas phase) everything points to a molec-ular self-assembly leading to an interdigitated smectic-like mesophase favored by a hydrogen bondmediated organization. This model can explain the appropriate space filling needed for compact molecular packing at the solid state, turning to a lamellar mesophase only when long alkyl-tails are present as well as the high melting point observed for these compounds.

\subsection{AFM studies}

Atomic force microscopy (AFM) is a useful tool to study the surface morphology and structure at the nanometer scale and hence, it helps in understanding the surface morphology to a greater extent. The thin film of compound AC5 was subjected to AFM study and the experiment was performed at room temperature. A thin film of compound AC5 was prepared on ITO glass plate from its acetone solution $(1 \mathrm{mg} / \mathrm{ml})$ via spin coating. Its $3 \mathrm{D}$ and topographic images are shown in Fig. 11. From the image, it was evident that the surface of the thin film is homogeneous studded with granular structures. The root mean square (rms) roughness value of film AC5 was found to be in the range of $\sim 7-148 \mathrm{~nm}( \pm 10 \mathrm{~nm})$. In order to explore the suitability of these compounds for device application, detailed investigations on the solvent effects, the morphology of thin films, and luminescence efficiency in film state are required. 


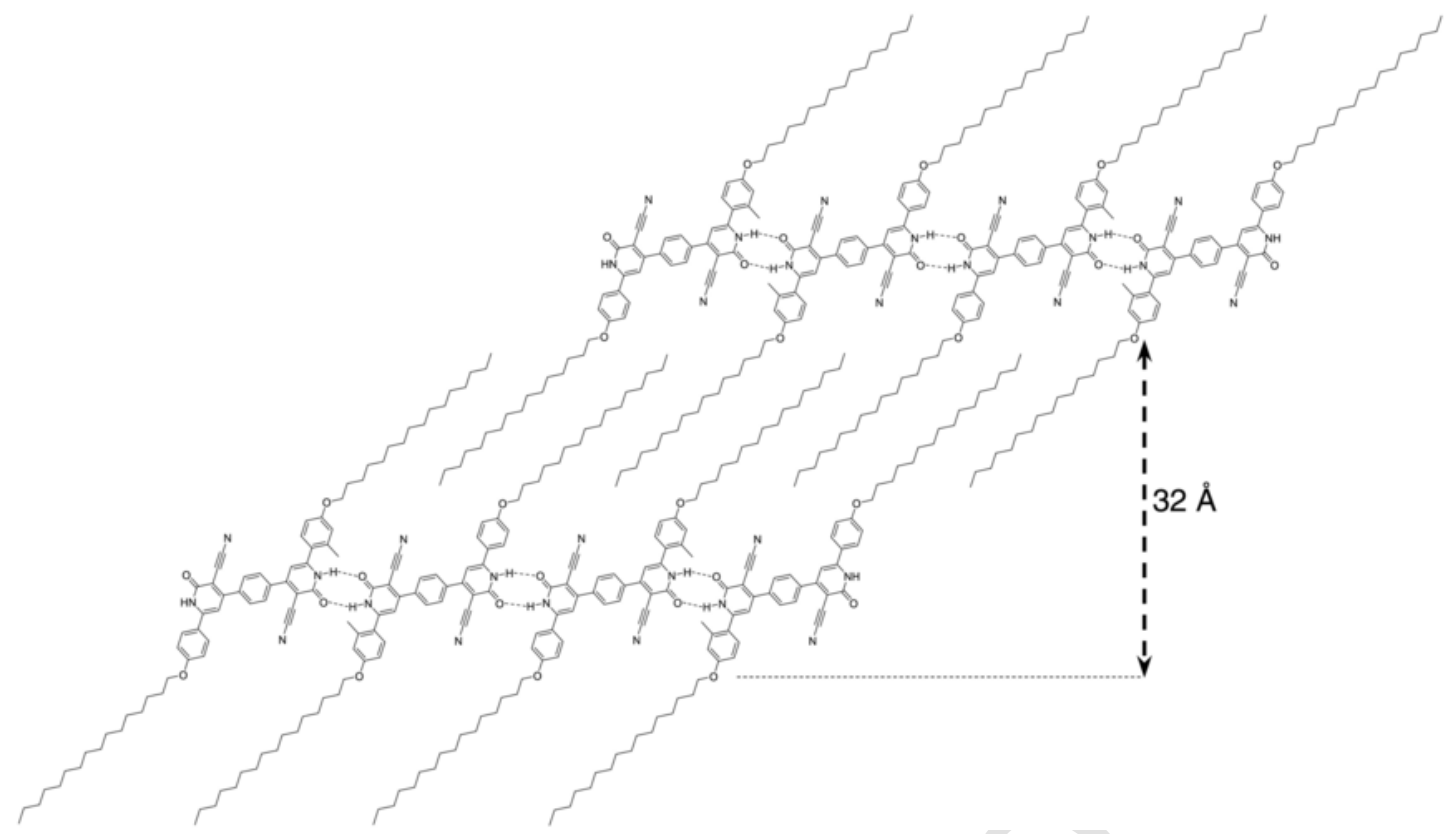

Fig. 8. Evaluated molecular self-assembling of the smectic mesophase of AC5.<smiles>COc1ccc(-c2cc(-c3ccc(-c4cc(-c5ccc(OC)cc5)[nH]c(=O)c4C#N)cc3)c(C#N)c(=O)[nH]2)cc1</smiles>

a)<smiles>CC(C)CC(C)C(C)C(C)C1C(C)C(C)C(C)C(C(C)C(C)C(C)C(C)C(C)C2C(C)C(C)C(C)C(C)C2C)C1C</smiles>

b)

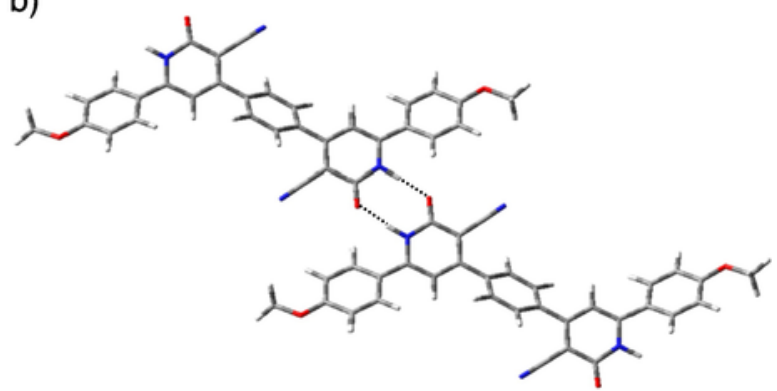

Fig. 9. Optimized structure (B3LYP-D3, 6-31G*) of model compound ACOMe (a) and the hydrogen-bonded dimer, HB-DIMER, (b).

\section{Conclusions}

A new series of compounds possessing molecular architecture based on cyanopyridone units were synthesized and investigated for photophysical and liquid crystal behavior. All the compounds are thermally stable up to $200^{\circ} \mathrm{C}$ and exhibit strong blue light emissive properties with considerably impressive quantum yield. Furthermore, it was ev-ident from the photophysical data that the variation of terminal linear alkoxy chain lengths in the compounds affects the absorption wave-length and molar extinction coefficient values. However only very long tails allow the stabilization of a liquid crystalline organization with a layered molecular arrangement.

\section{Experimental}

\subsection{Materials and methods}

All the reagents and solvents used in the current work were purchased from a commercial source and they were used without further purification. The synthesized compounds were purified and recrystallized from high purity solvents. UV-visible absorption and emission properties were measured using UV-1800 SHIMADZU UV-spectrophotometer and RF-5301 PC, SHIMADZU spectrophotometer equipped with a Xe-lamp as an excitation source, respectively. IR spectra were collected using Bruker ALPHA eco-ATR-IR on ZnSe Crystal. ${ }^{1} \mathrm{H}$ NMR $(400 \mathrm{MHz})$ and ${ }^{13} \mathrm{C}$ NMR $(100 \mathrm{MHz})$ on a Bruker spectrometer. The spectra were recorded at room temperature in deuterated dimethyl sulfoxide (DMSO- $d_{6}$ ). The chemical shifts are expressed in ppm values referenced to tetramethysilane (TMS). The 


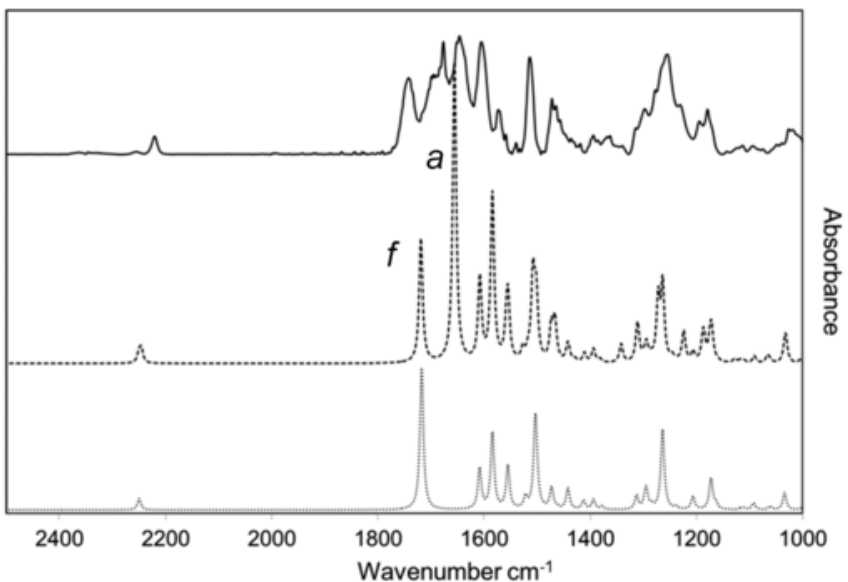

Fig. 10. FTIR spectrum of AC5 in $\mathrm{KBr}$ pellet (upper); calculated infrared spectra (B3LYP-D3, 6-31G*) of HB-DIMER (middle) and ACOMe (down).

mass spectra were obtained with Waters (SynaptG2) ESI-MS method with methanol as eluent. Cyclic voltammetry (CV) data were determined in a $\mathrm{N}_{2}$-saturated three-electrode system, where the working, counter, and reference electrodes are glassy carbon, platinum and $\mathrm{Ag} / \mathrm{Ag}^{+}$, respectively. The glassy carbon electrode was polished with $1.0 \mu \mathrm{m}$ alumina slurry and then sonicated for $10 \mathrm{~min}$ in distilled water. The sample solution (in DMSO+Acetone) was added into acetonitrile solution containing $0.1 \mathrm{M}$ tetrabuylammoniumhexafluorophosphate (TBAH) as the supporting electrolyte. Further, the electrochemical measurements were made at a scan rate of $50 \mathrm{mV} /$ $\mathrm{s}$. The $\mathrm{Ag} / \mathrm{Ag}^{+}$reference electrode was calibrated using a ferrocene/ ferrocenium $\left(\mathrm{Fc} / \mathrm{Fc}^{+}\right)$redox couples as an external standard. Atomic force microscopy (AFM) imaging was performed using A100-SGS AFM (A.P.E. Research, Trieste, Italy). The preliminary mesophase identification was based on microscopic examination of the textures formed by samples between two glass plates. NIKON and OLYMPUS $\mathrm{BH}-2$ polarizing microscopes equipped with a LINKAM THMS600 hot stage were used. The temperatures and enthalpies of the phase transitions were determined by calorimetric measurements with a DSC TA Instrument Q-20 system. Thermogravimetric analysis (TGA) was performed using a TA Q5000IR instrument at a heating rate of $10^{\circ} \mathrm{C} \mathrm{min}^{-1}$ under a nitrogen atmosphere. Molecular dimensions were estimated by molecular modeling (ChemSketch3D). The X-ray investigations on non-oriented samples were carried out in Lindemann capillary tubes (diameter $0.9 \mathrm{~mm}$ ) using a PINHOLE (ANTON-PAAR) film camera.

\subsection{Computational details}

Quantum chemical calculations were performed using the Gaussian 09 [35] suite programs. Geometry optimization was carried out in gas phase with the B3LYP method [36-38], with the van der Waals dispersion correction [39], employing 6-31G(d) [40] basis set. Geometry optimization were conducted without constraints, using the default convergence criteria for the Gaussian software. Vibrational frequency calculations were carried out at the same level of theory as the geometry optimizations and indicated that the stationary points were minima, lacking imaginaries frequencies. The energies of interaction were calculated, at the same level without and with correction for the BSSE using the Boys-Bernardi counterpoise technique [41], by subtracting the electronic energies of the optimized isolated partners of the electronic energy of the optimized noncovalent complex. The obtained electronic energy of interaction was corrected for scaled (0.9813) [42] zero-point energy differences (obtained from the frequency calculations described above).

\subsection{Preparation of aggregates for AIE measurements}

A $10^{-3} \mathrm{M}$ stock solution of compounds AC1-5 in DMSO/THF was prepared. Aliquots $(50 \mu \mathrm{L})$ of the stock solution were added to $5 \mathrm{~mL}$ volumetric flasks and diluted to volume with DMSO/THF and $\mathrm{H}_{2} \mathrm{O}$ in the proper ratios. Solutions were placed in a sonicator for $10 \mathrm{~min}$ before measurement [43].

\subsection{General procedure for the preparation of $\boldsymbol{A C 1 - 5}$}

The long chained alkoxyacetophenones (1b-e) were prepared according to the standard procedure [19]. Target compounds AC1-5 were synthesized by a one pot method depicted in Scheme 1. The mixture of methyl/alkoxyacetophenones (1a-e) $(0.02 \mathrm{~mol})$ with terephthaldehyde (2) $(0.01 \mathrm{~mol})$, ethyl cyanoacetate $(0.02 \mathrm{~mol})$ and ammonium acetate $(0.16 \mathrm{~mol})$ in 1,4 -dioxane was heated at $80^{\circ} \mathrm{C}$ for $8 \mathrm{~h}$. The reaction mixture was added drop wise into water and the precipitate was filtered, washed with ethyl acetate followed by ethanol, finally, the crude compound was recrystallized using mixture of chloroform and ethanol to obtain the pure product (AC1-5).

\subsubsection{Synthesis of 4,4'-(1,4-phenylene)bis(2-oxo-6-(p-tolyl)-1,2- dihydropyridine-3-carbonitrile) (AC1)}

According to the general procedure using mixture of 4-methylacetophenone (1a) $(2.68 \mathrm{~g}, 0.02 \mathrm{~mol})$ with terephthaldehyde (2) $(1.34 \mathrm{~g}$, $0.01 \mathrm{~mol})$, ethyl cyanoacetate $(2.26 \mathrm{~g}, 0.02 \mathrm{~mol})$ and ammonium acetate $(12.33 \mathrm{~g}, 0.16 \mathrm{~mol})$ in 1,4 -dioxane $(25 \mathrm{~mL})$ was heated at $80^{\circ} \mathrm{C}$ for $8 \mathrm{~h}$, the target compound $\mathbf{A C 1}$ was obtained as a yellow solid after
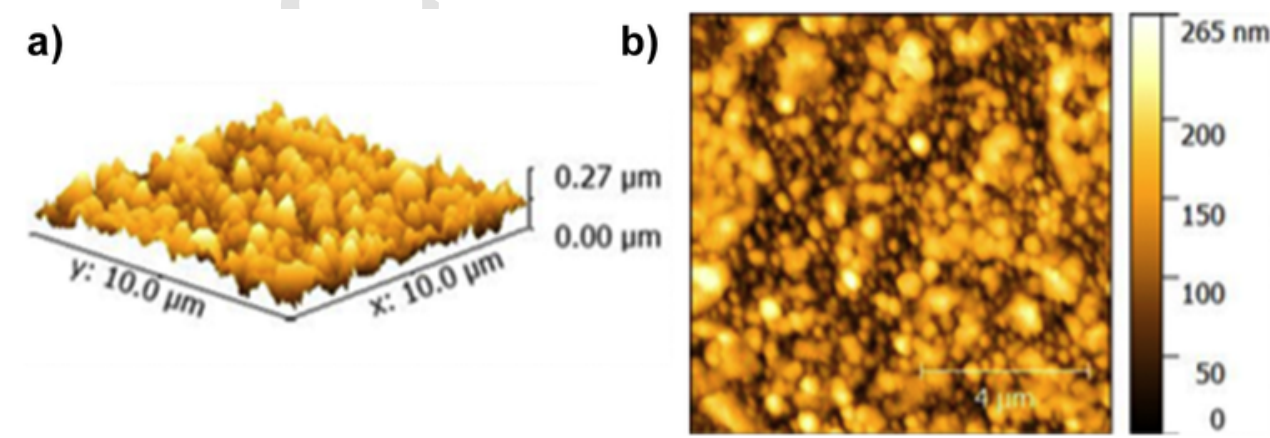

Fig. 11. AFM images of AC5 $(10 \times 10 \mu \mathrm{m})$ in (a) 3D perspective (b) Topographic image. 
purification. Yield 75\%, ATR-IR $\left(\mathrm{cm}^{-1}\right)$ : 3036, 2900, 2220, 1740, 1651, 1341. ${ }^{1} \mathrm{H}$ NMR (400 M Hz, DMSO- $\left.d_{6}\right) \delta(\mathrm{ppm}): 7.89$ (d, $J=8 \mathrm{~Hz}, 4 \mathrm{H}, \mathrm{Ar}-\underline{\mathrm{H}}), 7.76$ (s, 2H, Ar- $\underline{\mathrm{H}}), 7.67$ (s, 1H, Ar- $\underline{\mathrm{H}}), 7.42(1 \mathrm{H}$, $\operatorname{Ar}-\underline{\mathrm{H}}), 7.24$ (d, $J=8 \mathrm{~Hz}, 4 \mathrm{H}, \mathrm{Ar}-\underline{\mathrm{H}}), 6.76$ (s, 2H, Ar- $\underline{\mathrm{H}}), 3.54$ (s, 2H, Pyridine- $\mathrm{OH}), 1.80\left(\mathrm{~s}, 6 \mathrm{H},-\mathrm{CH}_{3}\right) .{ }^{13} \mathrm{C}$ NMR $\left(100 \mathrm{MHz}, \mathrm{DMSO}-d_{6}\right)$ $\delta$ (ppm): 172.78, 156.79, 151.09, 140.17, 139.79, 135.79, 134.83, 131.07, 130.34, 129.52, 128.73, 127.61, 119.71, 104.43, 22.16, 21.30. MS $(\mathrm{m} / \mathrm{z}):[\mathrm{M}+\mathrm{H}]^{+}$Found: 495.4; Calculated: 495.3. Anal. Calcd. for $\mathrm{C}_{32} \mathrm{H}_{22} \mathrm{~N}_{4} \mathrm{O}_{2}$ : C, 77.72; H, 4.48; N, 11.33. Found: C, 77.78; H, 4.50; $\mathrm{N}, 11.37$.

\subsubsection{Synthesis of 4,4'-(1,4-phenylene)bis(6-(4-butoxyphenyl)-2-oxo-} 1,2-dihydropyridine-3-carbonitrile) (AC2)

According to the general procedure using mixture of 4-butyloxyacetophenone (1b) $(3.84 \mathrm{~g}, 0.02 \mathrm{~mol})$ with terephthaldehyde (2) $(1.34 \mathrm{~g}, 0.01 \mathrm{~mol})$, ethyl cyanoacetate $(2.26 \mathrm{~g}, 0.02 \mathrm{~mol})$ and ammonium acetate $(12.33 \mathrm{~g}, 0.16 \mathrm{~mol})$ in 1,4-dioxane $(25 \mathrm{~mL})$ was heated at $80^{\circ} \mathrm{C}$ for $8 \mathrm{~h}$, the target compound $\mathbf{A C 2}$ was obtained as a yellow solid after purification. Yield 72\%, ATR-IR $\left(\mathrm{cm}^{-1}\right)$ : 3040, 2931, $2871,2216,1741,1634,1358 .{ }^{1} \mathrm{H}$ NMR $\left(400 \mathrm{M} \mathrm{Hz}, \mathrm{DMSO}-d_{6}\right) \delta$ (ppm): 7.89 (s, 6H, Ar- $\underline{\mathrm{H}}), 7.70-7.66(\mathrm{~m}, 1 \mathrm{H}, \mathrm{Ar}-\underline{\mathrm{H}}), 7.49-7.45(\mathrm{~m}$, $1 \mathrm{H}, \operatorname{Ar}-\underline{\mathrm{H}}), 7.00$ (d, $J=8 \mathrm{~Hz}, 4 \mathrm{H}, \operatorname{Ar}-\underline{\mathrm{H}}), 6.86-6.76(\mathrm{~m}, 2 \mathrm{H}, \operatorname{Ar}-\underline{\mathrm{H}})$, 4.06-4.02 (m, 4H, $\left.-\mathrm{OCH}_{2}-\right), 3.96(\mathrm{~s}, 2 \mathrm{H}$, Pyridine- $\mathrm{OH}), 1.73-1.66(\mathrm{~m}$, $\left.4 \mathrm{H},-\underline{\mathrm{C}}_{2}-\right), 1.47-1.38\left(\mathrm{~m}, 4 \mathrm{H},-\mathrm{CH}_{2}-\right), 0.92\left(\mathrm{t}, J=8 \mathrm{~Hz}, 6 \mathrm{H},-\mathrm{CH}_{3}\right) .{ }^{13} \mathrm{C}$ NMR (100 MHz, DMSO- $\left.d_{6}\right) \delta(\mathrm{ppm}): 181.66,147.93,140.47,137.47$, 131.11, 129.98, 129.13, 129.08, 115.28, 110.01, 109.99, 68.02, 31.05, 26.73, 19.10, 14.08. MS $(\mathrm{m} / \mathrm{z})$ : $[\mathrm{M}-\mathrm{H}]^{+}$Found: 609.2; Calculated: 609.2. Anal. Calcd. for $\mathrm{C}_{38} \mathrm{H}_{34} \mathrm{~N}_{4} \mathrm{O}_{4}$ : C, 74.73; H, 5.61; N, 9.17. Found: C, 74.79; H, 5.64; N, 9.12.

4.4.3. Synthesis of 4,4'-(1,4-phenylene)bis(6-(4-(hexyloxy)phenyl)-2oxo-1,2-dihydropyridine-3-carbonitrile) (AC3)

According to the general procedure using mixture of 4-hexyloxyacetophenone (1c) $(4.40 \mathrm{~g}, 0.02 \mathrm{~mol})$ with terephthaldehyde (2) $(1.34 \mathrm{~g}, 0.01 \mathrm{~mol})$, ethyl cyanoacetate $(2.26 \mathrm{~g}, 0.02 \mathrm{~mol})$ and ammonium acetate $(12.33 \mathrm{~g}, 0.16 \mathrm{~mol})$ in 1,4 -dioxane $(25 \mathrm{~mL})$ was heated at $80^{\circ} \mathrm{C}$ for $8 \mathrm{~h}$, the target compound AC3 was obtained as a yellow solid after purification. Yield 75\%, ATR-IR $\left(\mathrm{cm}^{-1}\right)$ : 3038, 2931, 2895, 2218, 1790, 1631, 1352. ${ }^{1} \mathrm{H}$ NMR (400 M Hz, DMSO- $\left.d_{6}\right) \delta$ (ppm): 7.93-7.85 (m, 6H, Ar- $\underline{\mathrm{H}}), 7.06-6.97$ (m, 6H, Ar- $\underline{\mathrm{H}}), 6.96$ (s, $2 \mathrm{H}, \mathrm{Ar}-\underline{\mathrm{H}}), 4.05-4.01\left(\mathrm{~m}, 4 \mathrm{H},-\mathrm{OCH}_{2}-\right), 3.9$ (s, 2H, Pyridine- $\left.\mathrm{OH}\right)$, $1.88\left(\mathrm{~s}, 2 \mathrm{H},-\mathrm{C}_{2}-\right), 1.72-1.68\left(\mathrm{~m}, 4 \mathrm{H},-\mathrm{CH}_{2}-\right), 1.39\left(\mathrm{~b}, 4 \mathrm{H},-\mathrm{CH}_{2}-\right.$ ), $1.28\left(\mathrm{~b}, 6 \mathrm{H},-\mathrm{CH}_{2}\right), 0.85\left(\mathrm{t}, J=6 \mathrm{~Hz}, 6 \mathrm{H},-\underline{\mathrm{CH}}_{3}\right) .{ }^{13} \mathrm{C} \mathrm{NMR}(100 \mathrm{MHz}$, DMSO- $\left.d_{6}\right) \delta$ (ppm): $170.89,170.36,161.63,159.89,159.11,158.58$, $141.37,140.76,130.88,129.90,127.66,127.33,125.41,124.23$, $122.45,120.76,119.72,118.95,118.48,115.22,107.97,68.30,31.39$, 28.96, 28.91, 25.54, 22.47, 14.31. MS $(\mathrm{m} / \mathrm{z})$ : $[\mathrm{M}+\mathrm{H}]^{+}$Found: 667.2; Calculated: 667.3. Anal. Calcd. for $\mathrm{C}_{42} \mathrm{H}_{42} \mathrm{~N}_{4} \mathrm{O}_{4}$ : C, 75.65; $\mathrm{H}, 6.35 ; \mathrm{N}$, 8.40. Found: C, 75.71; H, 6.38; N, 8.36.

4.4.4. Synthesis of 4,4'-(1,4-phenylene)bis(6-(4-(octyloxy)phenyl)-2oxo-1,2-dihydropyridine-3-carbonitrile) (AC4)

According to the general procedure using mixture of 4-octyloxyacetophenone (1d) $(4.96 \mathrm{~g}, 0.02 \mathrm{~mol})$ with terephthaldehyde (2) $(1.34 \mathrm{~g}, 0.01 \mathrm{~mol})$, ethyl cyanoacetate $(2.26 \mathrm{~g}, 0.02 \mathrm{~mol})$ and ammonium acetate $(12.33 \mathrm{~g}, 0.16 \mathrm{~mol})$ in 1,4 -dioxane $(25 \mathrm{~mL})$ was heated at $80^{\circ} \mathrm{C}$ for $8 \mathrm{~h}$, the target compound $\mathbf{A C 4}$ was obtained as a yellow solid after purification. Yield 82\%, ATR-IR $\left(\mathrm{cm}^{-1}\right)$ : 3010, 2921, 2854, $2218,1741,1638,1358 .{ }^{1} \mathrm{H}$ NMR $\left(400 \mathrm{M} \mathrm{Hz}, \mathrm{DMSO}-d_{6}\right) \delta(\mathrm{ppm})$ : 7.91-7.87 (m, 4H, Ar- $\underline{\mathrm{H}}), 7.54-7.25$ (m, 4H, Ar- $\underline{\mathrm{H}}), 7.08-6.74(\mathrm{~m}, 4 \mathrm{H}$, Ar- $\underline{\mathrm{H}}), 6.82-6.74(\mathrm{~m}, 2 \mathrm{H}, \mathrm{Ar}-\underline{\mathrm{H}}), 4.04-4.01\left(\mathrm{~m}, 4 \mathrm{H},-\mathrm{OC}_{2}-\right), 3.25$ (s, $2 \mathrm{H}$, Pyridine- $\mathrm{O} \underline{\mathrm{H}}), 1.71-1.68$ (b, 4H, $\left.-\mathrm{C}_{2}-\right), 1.39-$ $1.19\left(\mathrm{~b}, 20 \mathrm{H},-\mathrm{CH}_{2}-\right), 0.84\left(\mathrm{~s}, 6 \mathrm{H},-\mathrm{CH}_{3}\right) \cdot{ }^{13} \mathrm{C} \mathrm{NMR}(100 \mathrm{MHz}$, DMSO- $\left.d_{6}\right) \delta(\mathrm{ppm}): 179.62,174.68,162.99,161.59,140.59,130.94$, $130.88,130.75,130.50,129.88,129.03,128.42,128.25,127.92$, 125.93, 122.18, 116.85, 113.16, 105.66, 105.24, 68.29, 31.65, 29.07, 25.88, 22.49, 14.36. MS $(\mathrm{m} / \mathrm{z}):[\mathrm{M}+\mathrm{H}]^{+}$Found: 723.3; Calculated: 723.3. Anal. Calcd. for $\mathrm{C}_{46} \mathrm{H}_{50} \mathrm{~N}_{4} \mathrm{O}_{4}$ : C, 76.43; $\mathrm{H}, 6.97 ; \mathrm{N}, 7.75$. Found: C, 76.48; H, 7.01; N, 7.79.

4.4.5. Synthesis of 4,4'-(1,4-phenylene)bis(6-(4-

(hexadecyloxy)phenyl)-2-oxo-1,2-dihydropyridine-3-carbonitrile) (AC5)

According to the general procedure using mixture of 4-hexadecyloxyacetophenone (1e) $(7.21 \mathrm{~g}, 0.02 \mathrm{~mol})$ with terephthaldehyde (2) $(1.34 \mathrm{~g}, 0.01 \mathrm{~mol})$, ethyl cyanoacetate $(2.26 \mathrm{~g}, 0.02 \mathrm{~mol})$ and ammonium acetate $(12.33 \mathrm{~g}, 0.16 \mathrm{~mol})$ in 1,4-dioxane $(25 \mathrm{~mL})$ was heated at $80^{\circ} \mathrm{C}$ for $8 \mathrm{~h}$, the target compound AC5 was obtained as a yellow solid after purification. Yield $80 \%$, ATR-IR $\left(\mathrm{cm}^{-1}\right): 3035,2919,2849$, 2220, 1739, 1675, 1381. ${ }^{1} \mathrm{H}$ NMR (400 M Hz, DMSO- $\left.d_{6}\right) \delta(\mathrm{ppm})$ :

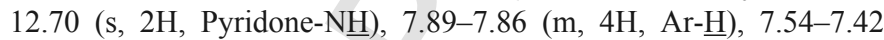
(m, 4H, Ar- $\underline{\mathrm{H}}), 7.37-7.29$ (m, 2H, Ar- $\underline{\mathrm{H}}), 7.03-6.94$ (m, 4H, Ar- $\underline{\mathrm{H}})$, 4.03-3.99 (m, 4H, - $\left.\underline{\mathrm{H}}_{2}-\right), 1.72-1.65\left(\mathrm{~m}, 4 \mathrm{H},-\mathrm{CH}_{2^{-}}\right), 1.37(\mathrm{~b}, 4 \mathrm{H}$, $\left.-\mathrm{CH}_{2}-\right), 1.20\left(\mathrm{~b}, 48 \mathrm{H},-\mathrm{CH}_{2}-\right), 0.83-0.80\left(\mathrm{~m}, 6 \mathrm{H},-\mathrm{CH}_{3}\right) .{ }^{13} \mathrm{C} \mathrm{NMR}$ $\left(100 \mathrm{MHz}, \mathrm{DMSO}-d_{6}\right) \delta(\mathrm{ppm}): 174.89,163.00,143.76,142.28$, $135.20,130.87,129.97,129.95,129.92,129.88,128.47,115.23$, $114.69,114.66,113.45,105.00,82.03,80.86,68.28,31.71,29.44$, 29.36, 29.11, 26.78, 25.83, 22.50, 14.35. MS $(\mathrm{m} / \mathrm{z}):\left[\mathrm{M}+\mathrm{CH}_{3} \mathrm{CN}\right]^{+}$ Found: 989.1; Calculated: 989.1. Anal. Calcd. for $\mathrm{C}_{62} \mathrm{H}_{82} \mathrm{~N}_{4} \mathrm{O}_{4}$ : C, 78.61; H, 8.72; N, 5.91. Found: C, 78.68; H, 8.75; N, 5.87.

\section{Uncited reference}

\section{[11]}

\section{Acknowledgments}

This research was supported by the Science \& Engineering Research Board (SERB) under Young Scientists Scheme (Project File no.: YSS/2014/000835), Govt. of India, New Delhi. The author acknowledges the Mysore University, Mysore for the instrumental analysis. The authors also acknowledge the Ape instrument, Italy for AFM analysis. J. B. and M. B. R. have been financially supported by MINECO-FEDER of Spain-UE (Projects MAT2014-55205-P, CTQ2015-70174P, and MAT2015-66208-C3-1-P) and the Aragón Government and FSE (Project E04). Special thanks to Thermal Analysis Services from the Instituto de Ciencia de Materiales de Aragón, Universidad de Zaragoza-CSIC (Spain).

\section{Appendix A. Supplementary data}

Supplementary data to this article can be found online at https:// doi.org/10.1016/j.molliq.2018.01.126.

\section{References}

[1] S. Xue, X. Qiu, Q. Sun, W. Yang, Alkyl length effects on solid-state fluorescence and mechanochromic behavior of small organic luminophores, J. Mater. Chem. C 4 (2016) 1568-1578.

[2] J. Mei, Z. Bao, Side chain engineering in solution-processable conjugated polymers, Chem. Mater. 26 (2013) 604-615.

[3] F. Zhang, Y. Hu, T. Schuettfort, C.-a. Di, X. Gao, C.R. McNeill, L. Thomsen, S.C. Mannsfeld, W. Yuan, H. Sirringhaus, Critical role of alkyl chain branching of organic semiconductors in enabling solution-processed n-channel organic thin-film transistors with mobility of up to $3.50 \mathrm{~cm}^{2} \mathrm{~V}^{-1} \mathrm{~s}^{-1}$, J. Am. Chem. Soc. 135 (2013) 2338-2349. 
[4] J.Y. Back, T.K. An, Y.R. Cheon, H. Cha, J. Jang, Y. Kim, Y. Baek, D.S. Chung, S.-K. Kwon, C.E. Park, Alkyl chain length dependence of the field-effect mobility in novel anthracene derivatives, ACS Appl. Mater. Interfaces 7 (2014) 351-358.

[5] W. Liu, Y. Wang, L. Bu, J. Li, M. Sun, D. Zhang, M. Zheng, C. Yang, S. Xue, W. Yang, Chain length-dependent piezofluorochromic behavior of 9, 10-bis (p-alkoxystyryl) anthracenes, J. Lumin. 143 (2013) 50-55.

[6] Y. Wang, Y. Liao, C.P. Cabry, D. Zhou, G. Xie, Z. Qu, D.W. Bruce, W. Zhu, Highly efficient blueish-green fluorescent OLEDs based on AIE liquid crystal molecules: from ingenious molecular design to multifunction materials, J. Mater. Chem. C 5 (2017) 3999-4008.

[7] B. Tang, A. Qin, Aggregation-induced emission: fundamentals, 2013 search PubMed; AYN Hong, JWY Lam and BZ Tang, Chem. Soc. Rev. 40 (2011) 5361-5388.

[8] Q. Wu, Q. Peng, T. Zhang, Z. Shuai, Theoretical study on the aggregation induced emission, Sci. Sin. Chim. 43 (2013) 1078-1089.

[9] Z. Chi, X. Zhang, B. Xu, X. Zhou, C. Ma, Y. Zhang, S. Liu, J. Xu, Recent advances in organic mechanofluorochromic materials, Chem. Soc. Rev. 41 (2012) $3878-3896$

[10] T.N. A., A.V. Adhikari, New cyanopyridone based luminescent liquid crystalline materials: synthesis and characterization, Photochem. Photobiol. Sci. 13 (2014) 1496-1508.

[11] S.-J. Su, H. Sasabe, T. Takeda, J. Kido, Pyridine-containing bipolar host materials for highly efficient blue phosphorescent OLEDs, Chem. Mater. 20 (2008) 1691-1693.

[12] C. Tang, T. Yang, X. Cao, Y. Tao, F. Wang, C. Zhong, Y. Qian, X. Zhang, W. Huang, Tuning a weak emissive blue host to highly efficient green dopant by a $\mathrm{CN}$ in tetracarbazolepyridines for solution-processed thermally activated delayed fluorescence devices, Adv. Opt. Mater. 3 (2015) 786-790.

[13] A. Pavlyuchenko, N. Smirnova, T. Mikhailova, E. Kovshev, V. Titov, Synthesis and liquid-crystalline properties of 2-(4-alkyl-or 4-alkoxyphenyl)-5-cyanopyridines, In: Chemischer Informationsdienst, 17, 1986.

[14] L.D. Farrand, M. Heckmeier, Cyanopyridone derivatives as liquid crystals, In: US Patent 7,442,475 B2, 2008.

[15] E.J. Foster, R.B. Jones, C. Lavigueur, V.E. Williams, Structural factors controlling the self-assembly of columnar liquid crystals, J. Am. Chem. Soc. 128 (2006) $8569-8574$.

[16] R. Kleppinger, C.P. Lillya, C. Yang, Self-assembling discotic mesogens, Angew Chem. Int. Ed. Engl. 34 (1995) 1637-1638.

[17] M. Suárez, J.-M. Lehn, S.C. Zimmerman, A. Skoulios, B. Heinrich, Supramolecular liquid crystals. Self-assembly of a trimeric supramolecular disk and its self-organization into a columnar discotic mesophase, J. Am. Chem. Soc. 120 (1998) 9526-9532.

[18] H.-T. Nguyen, C. Destrade, J. Malthécte, Phasmids and Polycatenar Mesogens, Adv. Mater. 9 (1997) 375-388.

[19] T. Kitamura, C.H. Lee, H. Taniguchi, M. Matsumoto, Y. Sano, Preparation and coupling reactions of alkynyl(phenyl)iodonium salts bearing long alkoxy chains Formation of liquid-crystalline diacetylenes, J. Org. Chem. 59 (1994) 8053-8057.

[20] C. Trupthi Devaiah, B. Hemavathi, T.N. Ahipa, New blue emissive conjugated small molecules with low lying HOMO energy levels for optoelectronic applications, Spectrochim. Acta A Mol. Biomol. Spectrosc. 175 (2017) 222-228.

[21] C.-K. Shin, H. Lee, Effect of alkyl side-chain length and solvent on the luminescent characteristics of poly(3-n-alkylthiophene), Synth. Met. 140 (2004) 177-181.

[22] B.N. Veerabhadraswamy, H.K. Dambal, D.S.S. Rao, C.V. Yelamaggad, s-Triazine-based functional discotic liquid crystals: synthesis, mesomorphism and photoluminescence, ChemPhysChem 17 (2016) 2225-2237.

[23] D.F. Eaton, Reference materials for fluorescence measurement, Pure Appl. Chem. 60 (1988) 1107-1114.

[24] H.J. Yvon, A Guide to Recording Fluorescence Quantum Yields, HORIBA, Jobin Yvon Ltd., Stanmore, Middlesex, UK, 2012.

[25] J. Drobnik, E. Yeargers, On the use of quinine sulfate as a fluorescence standard, J. Mol. Spectrosc. 19 (1966) 454-455.

[26] Y. Wang, W. Liu, L. Bu, J. Li, M. Zheng, D. Zhang, M. Sun, Y. Tao, S. Xue, W. Yang, Reversible piezochromic luminescence of 9,10-bis[(N-alkylcarbazol-3- yl)vinyl]anthracenes and the dependence on $\mathrm{N}$-alkyl chain length, J. Mater. Chem. C 1 (2013) 856-862.

[27] A. Iwan, D. Sȩk, J. Kasperczyk, Characterization and photoluminescence study of blue and green emitting polyketanils and their blends, Macromolecules 38 (2005) 4384-4392.

[28] S. Kumar, P. Singh, R. Srivastava, R.R. Koner, A. Pramanik, J. Mathew, S. Sinha, M. Rawat, R.S. Anand, S. Ghosh, Engineering fused coumarin dyes: a molecular level understanding of aggregation quenching and tuning electroluminescence via alkyl chain substitution, J. Mater. Chem. C 2 (2014) 6637-6647.

[29] J. He, B. Xu, F. Chen, H. Xia, K. Li, L. Ye, W. Tian, Aggregation-induced emission in the crystals of 9,10-distyrylanthracene derivatives: the essential role of restricted intramolecular torsion, J. Phys. Chem. C 113 (2009) 9892-9899.

[30] G. Haberhauer, R. Gleiter, C. Burkhart, Planarized intramolecular charge transfer: a concept for fluorophores with both large stokes shifts and high fluorescence quantum yields, Chem Eur J 22 (2016) 971-978.

[31] B. Carlotti, R. Flamini, I. Kikaš, U. Mazzucato, A. Spalletti, Intramolecular charge transfer, solvatochromism and hyperpolarizability of compounds bearing ethenylene or ethynylene bridges, Chem. Phys. 407 (2012) 9-19.

[32] M.L. Tang, A.D. Reichardt, P. Wei, Z. Bao, Correlating carrier type with frontier molecular orbital energy levels in organic thin film transistors of functionalized acene derivatives, J. Am. Chem. Soc. 131 (2009) 5264-5273.

[33] C.-H. Chen, W.-S. Huang, M.-Y. Lai, W.-C. Tsao, J.T. Lin, Y.-H. Wu, T.-H. Ke, L.-Y. Chen, C.-C. Wu, Versatile, benzimidazole/amine-based ambipolar compounds for electroluminescent applications: single-layer, blue, fluorescent OLEDs, hosts for single-layer, phosphorescent OLEDs, Adv. Funct. Mater. 19 (2009) 2661-2670.

[34] D. Chopra, T.P. Mohan, B. Vishalakshi, T.N.G. Row, 4-(4-Fluoro-3-phenoxyphenyl)-6-(4-fluorophenyl)-2-oxo-1,2-dihydropyridin e-3-carbonitrile and the 6-(4-methylphenyl)-analogue, Acta Crystallogr. Sect. C: Cryst. Struct. Commun. 62 (2006) O540-O543.

[35] M.J. Frisch, G.W. Trucks, H.B. Schlegel, G.E. Scuseria, M.A. Robb, J.R. Cheeseman, G. Scalmani, V. Barone, G.A. Petersson, H. Nakatsuji, X. Li, M Caricato, A. Marenich, J. Bloino, B.G. Janesko, R. Gomperts, B. Mennucci, H.P Hratchian, J.V. Ortiz, A.F. Izmaylov, J.L. Sonnenberg, D. Williams-Young, F. Ding, F. Lipparini, F. Egidi, J. Goings, B. Peng, A. Petrone, T. Henderson, D. Ranasinghe, V.G. Zakrzewski, J. Gao, N. Rega, G. Zheng, W. Liang, M. Hada, M. Ehara, K. Toyota, R. Fukuda, J. Hasegawa, M. Ishida, T. Nakajima, Y. Honda, O. Kitao, H. Nakai, T. Vreven, K. Throssell, J.A. Montgomery Jr., J.E. Peralta, F. Ogliaro, M. Bearpark, J.J. Heyd, E. Brothers, K.N. Kudin, V.N Staroverov, T. Keith, R. Kobayashi, J. Normand, K. Raghavachari, A. Rendell, J.C. Burant, S.S. Iyengar, J. Tomasi, M. Cossi, J.M. Millam, M. Klene, C. Adamo, R. Cammi, J.W. Ochterski, R.L. Martin, K. Morokuma, O. Farkas, J.B. Foresman, D.J. Fox, R.A. Gaussian 09, Gaussian, Inc., Wallingford CT, 2016.

[36] C.T. Lee, W.T. Yang, R.G. Parr, Development of the colle-salvetti correlation-energy formula into a functional of the electron-density, Phys. Rev. B 37 (1988) 785-789.

[37] A.D. Becke, Density-functional thermochemistry .3. The role of exact exchange, J. Chem. Phys. 98 (1993) 5648-5652.

[38] A.D. Becke, A new mixing of hartree-fock and local density-functional theories, J. Chem. Phys. 98 (1993) 1372-1377.

[39] S. Grimme, J. Antony, S. Ehrlich, H. Krieg, A consistent and accurate ab initio parametrization of density functional dispersion correction (DFT-D) for the 94 elements H-Pu, J. Chem. Phys. 132 (2010), 154104.

[40] R. Ditchfield, W.J. Hehre, J.A. Pople, Self-consistent molecular-orbital methods. IX. An extended Gaussian-type basis for molecular-orbital studies of organic molecules, J. Chem. Phys. 54 (1971) 724-728.

[41] S.F. Boys, F. Bernardi, Calculation of small molecular interactions by differences of separate Total energies - some procedures with reduced errors, Mol. Phys. 19 (1970) 553-566.

[42] J.P. Merrick, D. Moran, L. Radom, An evaluation of harmonic vibrational frequency scale factors, J. Phys. Chem. A 111 (2007) 11683-11700.

[43] X.Y. Shen, Y.J. Wang, E. Zhao, W.Z. Yuan, Y. Liu, P. Lu, A. Qin, Y. Ma, J.Z. Sun, B.Z. Tang, Effects of substitution with donor-acceptor groups on the properties of tetraphenylethene trimer: aggregation-induced emission, solvatochromism, and mechanochromism, J. Phys. Chem. C 117 (2013) 7334-7347. 